NASA Technical Memorandum 103198

\title{
H-Infinity Based Integrated Flight/ Propulsion Control Design for a STOVL Aircraft in Transition Flight
}

Sanjay Garg and Duane L. Mattern

Sverdrup Technology, Inc.

Lewis Research Center Group

Brook Park, Ohio

and

Michelle M. Bright and Peter J. Ouzts

National Aeronautics and Space Administration

Lewis Research Center

Cleveland, Ohio

Prepared for the

Guidance, Navigation and Control Conference

sponsored by the American Institute of Aeronautics and Astronautics

Portland, Oregon, August 20-22, 1990

\section{N/SA}

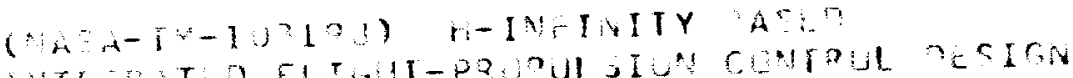

$\operatorname{ivg} 3-2 \cos 1$

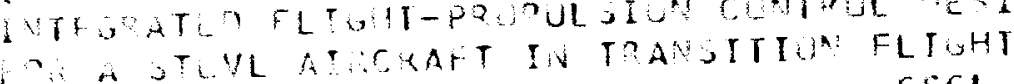

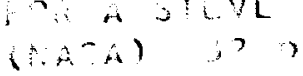

$\mathrm{CSCL} O \mathrm{IC}$

$3 / 0 \% \quad 0 ? 3519$ 



\title{
H-INFINITY BASED INTEGRATED FLIGHT/PROPULSION CONTROL DESIGN FOR A STOVL AIRCRAFT IN TRANSITION FLIGHT
}

\author{
Sanjay Garg' and Duane L. Mattern ${ }^{2}$ \\ Sverdrup Technology, Inc. \\ Lewis Research Center Group \\ Brook Park, Ohio 44142 \\ Michelle M. Bright ${ }^{3}$ and Peter J. Ouzts ${ }^{4}$ \\ National Aeronautics and Space Administration \\ Lewis Research Center \\ Cleveland, Ohio 44135
}

\begin{abstract}
This paper presents results from an application of $\mathrm{H}_{\infty}$ control design methodology to
\end{abstract} a centralized integrated flight/propulsion control (IFPC) system design for a supersonic Short Take-Off and Vertical Landing (STOVL) fighter aircraft in transition flight. The overall design methodology consists of a centralized IFPC controller design with controller partitioning. Only the feedback controller design portion of the methodology is addressed in this paper. Design and evaluation vehicle models are summarized, and insight is provided into formulating the $\mathrm{H}_{\mathrm{w}}$ control problem such that it reflects the IFPC design objectives. The $\mathrm{H}_{\infty}$ controller is shown to provide decoupled command tracking for the design model. The controller order could be significantly reduced by modal residualization of the "fast" controller modes without any deterioration in performance. The paper concludes with a discussion of the areas in which the controller performance needs to be improved, and ways in which these improvements can be achieved within the framework of an $\mathrm{H}_{\infty}$ based linear control design.

1Project Engineer, Senior Member AIAA

2Project Engineer, Member AIAA

${ }^{3}$ Aerospace Engineer, Member AIAA

${ }^{4}$ Aerospace Engineer 


\section{Introduction}

The trend in future military fighter/tactical aircraft design is towards aircraft with new/enhanced maneuver capabilities such as Short Take-Off and Vertical Landing (STOVL) and high angle of attack performance. An integrated flight/propulsion control (IFPC) system is required in order to obtain these enhanced capabilities with reasonable pilot workload. An integrated approach to control design is then necessary to achieve an effective IFPC system. Two very different approaches to IFPC design that have appeared in the recent literature are a centralized Linear Quadratic Gaussian - Loop Transfer Recovery (LQG/LTR) based approach [1] and a decentralized, hierarchical approach using Linear Quadratic Regulator (LQR) based explicit model-following for control synthesis [2]. These methodologies were evaluated in Refs. [3] and [4] to assess their strengths and weaknesses as part of an ongoing STOVL IFPC program at NASA Lewis Research Center. The objectives of this program are to develop a viable alternative to the existing integrated control design methodologies which will allow for improved system performance and simplicity of control law synthesis and implementation, and demonstrate the applicability of the methodology to a supersonic STOVL fighter aircraft.

Based on the experience gained from the studies documented in [3] and [4], the IFPC design methodology that is taking shape at NASA Lewis is referred to as IMPAC Integrated Methodology for Propulsion and Aircraft Control. The linear control design portion of the IMPAC approach consists of three major design steps : (i) Design of a centralized feedback controller to provide command tracking and stability and performance robustness considering the fully integrated airframe/propulsion model as one high-order system, (ii) Partitioning of the centralized controller into a decentralized, hierarchical form compatible with state-of-the-art IFPC implementations, and (iii) Design of command shaping prefilters from pilot control effectors to commanded variables to provide the overall desired response to pilot inputs. The IMPAC design approach is similar to that used in the example study in Ref. [3] except that in IMPAC the centralized controller will 
be designed using $\mathrm{H}_{\infty}$ synthesis techniques $[5,6]$ and a decentralized, hierarchical controller partitioning scheme will be used, whereas LQG/LTR synthesis and partitioning with output cross-feed were used in [3]. The notion of controller partitioning is discussed in some detail in Ref. [7]. Research is currently ongoing under the IMPAC program to develop techniques for partitioning the centralized controller into decentralized airframe and propulsion sub-system controllers that fit the hierarchical structure of Refs. [2] and [4] with no significant loss in closed-loop tracking performance and robustness. The command shaping prefilters will be designed using the multivariable bandlimited inverse method of Ref. [8] which was successfully used in [1] and [3].

Recent advances in $\mathrm{H}_{\infty}$ control theory [5,6] and computational algorithms to solve for $\mathrm{H}_{\infty}$ optimal control laws [9] have made this theory a viable candidate to be applied to complex multivariable control design problems. Some example applications of $\mathrm{H}_{\infty}$ control theory to flight control design appear in Refs. [10-12]. The objective of this paper is to investigate the applicability of $\mathrm{H}_{\infty}$ control theory to the centralized feedback controller design portion of the IMPAC approach. Towards this goal results are presented from a preliminary $\mathrm{H}_{\infty}$ based IFPC design for a linear model of a STOVL aircraft in transition flight.

The paper is organized as follows. The vehicle models to be used for control design and evaluation are first discussed. The $\mathrm{H}_{\infty}$ control design is then presented along with some discussion of the formulation of the IFPC design objectives within the framework of the $\mathrm{H}_{\infty}$ control problem. Evaluation results are presented for a reduced order approximation of the $\mathrm{H}_{\infty}$ controller with both the linear design model and a "pseudo-nonlinear" evaluation model. The paper concludes with a discussion of the areas in which the controller performance needs to be improved and ways in which these improvements can be achieved within the framework of the $\mathrm{H}_{\infty}$ linear control design problem. 


\section{Vehicle Model}

The vehicle considered in this study is representative of the delta winged E7-D supersonic STOVL airframe powered by a high bypass turbofan engine [13]. The aircraft is equipped with ejectors to provide propulsive lift at low speeds and hover; a 2D-CD vectoring aft nozzle with afterburner for supersonic flight; a vectoring ventral nozzle for pitch control and lift augmentation during transition; and jet reaction control systems (RCS) for pitch, roll and yaw control during transition and hover. Schematic diagram of the aircraft with relative location of the various control effectors mentioned above is shown in Fig. 1. Engine compressor bleed flow is used for the RCS thrusters and the primary (mixed) engine flow is used for lift with ejector augmentation. Detailed ducting diagrams of the engine and discussion of the ejector STOVL concept are available in Ref. [13].

Currently, two separate computer simulations, one for the airframe and one for the propulsion system, are being used to assess performance capabilities of the aircraft and to generate open-loop linear models for control design [13]. The airframe simulation is a six degree-of-freedom nonlinear simulation using wind-tunnel test data for airframe stability derivatives and a simplified "actuator" type model of the propulsion system performance. The propulsion system simulation is a detailed turbofan engine aero-thermo cycle-deck. For a given flight condition, a linear 10th order aerodynamic model of the airframe is first obtained from the aircraft simulation and then a 5 th order propulsion model is obtained from the engine cycle-deck simulation corresponding to the trimmed values of ejector, ventral and main nozzle thrusts for the small perturbation airframe model. The airframe model control inputs consist of aerodynamic control surface deflections, the three engine thrusts along with the two nozzle deflection angles, and the five RCS thrusts. The wing tip roll RCS thrusters can provide either upward or downward thrust. The airframe model outputs are the standard six dof outputs such as the three axes velocities, accelerations, attitudes and rates etc. The engine model inputs are the control inputs such as fuel flow, and nozzle areas etc., and disturbance inputs such as ventral and main nozzle angles to 
model the effect of thrust vectoring on engine dynamics, compressor bleed flow to model effect of on-demand RCS thrusters, and flight Mach No. and altitude to model the effect of varying flight condition. The engine model outputs are the two rotor speeds, temperatures, pressures etc. along with the three thrusts.

A "pseudo-nonlinear" integrated airframe/propulsion model was created by interconnecting the small perturbation airframe and engine models, and complete nonlinear models for the RCS thrusters, airframe actuators and engine actuators and sensors as shown in Fig. 2. The airframe sensor dynamics will be added to the "pseudo-nonlinear" simulation in the future. A detailed description of the RCS and airframe actuator models is available in Ref. [14], and engine actuators and sensors are described in detail in Ref. [15]. In Fig. 2, the subscript " $a$ " refers to airframe quantities, " $e$ " refers to engine quantities, " $R$ " refers to Reaction Control System, " $c$ " refers to commanded inputs to the actuator models, and "o" refers to trim values of inputs and outputs about which the linear perturbation models are obtained. The inputs to the RCS model are the commands to the 5 RCS nozzle area actuators, the interface from the engine to the RCS is through the compressor bleed flow total temperature and pressure, and the interface from the airframe to the RCS is through dynamic pressure and angle of attack which model the RCS thrust augmentation effects [14]. The interface from RCS to airframe model is through the RCS thrusts and from RCS to engine model is through the total RCS bleed flow demand. Based on the earlier discussion of the airframe and engine models, the interface from the airframe to the engine is mainly through Mach No. and altitude, and that from engine to airframe is mainly through the three thrusts.

There are many reasons for forming a "pseudo-nonlinear" model such as that shown in Fig. 2. First, such a model provides a baseline from which linear integrated airframe/engine models can be obtained for IFPC design. Second, linear controller designs can be quickly evaluated through simulations to ensure that desired performance is maintained in the presence of realistic actuator and sensor dynamics, and that 
nonlinearities such as control and rate limits do not create any instabilities or lead to excessive deterioration in performance. Third, by stringing together a set of linear airframe and engine models, "pseudo-nonlinear" simulations of the type shown in Fig. 2 could be used to design and evaluate scheduling of controller parameters with a faster design turn-around time as opposed to using the detailed non-linear simulations in the intermediate design steps. Details of the pseudo-nonlinear build-up for the E-7D aircraft are discussed in Ref. [16].

The "pseudo-nonlinear" model for the E-7D as discussed above consists of more than 60 state variables, 18 control inputs and over 100 outputs. A reduced order integrated model for linear point-design was obtained by first linearizing the "pseudo-nonlinear" model about the trim values of the control effectors, residualizing the actuator and sensor modes using modal residualization techniques [17], and then selecting the inputs and outputs that are of interest for IFPC design. The resulting design model is of the form

$$
\dot{\bar{x}}=A \bar{x}+B \bar{u} ; \bar{y}=C \bar{x}+D \bar{u}
$$

where the state vector is

with

$$
\overline{\mathrm{x}}=[\mathrm{u}, \mathrm{v}, \mathrm{w}, \mathrm{p}, \mathrm{q}, \mathrm{r}, \phi, \theta, \psi, \mathrm{h}, \mathrm{N} 2, \mathrm{~N} 25, \mathrm{~T} 41, \mathrm{~T} 3, \mathrm{P} 6]^{\mathrm{T}}
$$

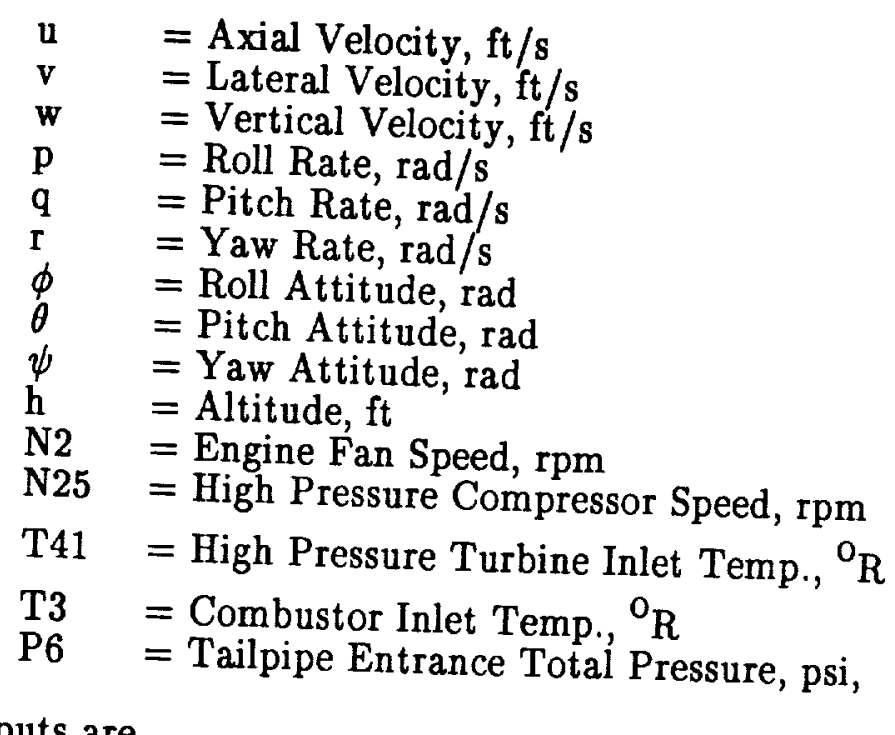




$$
\overline{\mathrm{u}}=[£, \delta \mathrm{a}, \delta \mathrm{r}, \mathrm{AQR}, \mathrm{AYR}, \mathrm{ARR}, \mathrm{WF}, \mathrm{A} 8, \mathrm{ETA}, \mathrm{A} 78, \mathrm{ANG} 8, \mathrm{ANG} 79]^{\mathrm{T}}
$$

with

$$
\begin{array}{ll}
\delta \mathrm{e} & =\text { Elevator Deflection, deg } \\
\delta \mathrm{a} & =\text { Aileron Deflection, deg } \\
\delta \mathrm{r} & =\text { Rudder Deflection, deg } \\
\text { AQR } & =\text { Pitch RCS Area, in } \\
\text { AYR } & =\text { Yaw RCS Area, in } \\
\text { ARR } & =\text { Roll RCS Area, in } \\
\text { WF } & =\text { Fuel Flow Rate, lbm/hr } \\
\text { A8 } & =\text { Aft Nozzle Throat Area, in } \\
\text { ETA } & =\text { Ejector Butterfly Angle, deg } \\
\text { A78 } & =\text { Ventral Nozzle Area, in } \\
\text { ANG8 } & =\text { Aft Nozzle Vectoring Angle, deg } \\
\text { ANG79 } & \text { Ventral Nozzle Vectoring Angle, deg, }
\end{array}
$$

and the outputs are

$$
\bar{y}=[V, V \operatorname{dot}, \theta, q, h d o t, \phi, p, \beta, r, N 2]^{T}
$$

with

$$
\begin{array}{ll}
\mathrm{V} & =\text { True Airspeed, } \mathrm{ft} / \mathrm{s} \\
\text { Vdot } & =\text { Total Acceleration, } \mathrm{ft} / \mathrm{s}^{2} \\
\text { hdot } & =\text { Climb Rate, } \mathrm{ft} / \mathrm{s} \\
\beta & =\text { Sideslip Angle, } \mathrm{deg} .
\end{array}
$$

The other outputs are as discussed under state description except that the angular positions and rates are in degrees.

The details of how the design model was generated from the "pseudo-nonlinear" model are available in Ref. [16], however some discussion of the choice of control inputs is relevant here. For instance, the E-7D aircraft is equipped with left and right elevons on the trailing edge of the delta wing. Collective deflection of the elevons provides the classical elevator pitch control while differential use of the elevons provides the aileron roll control. So the elevator $\left(\delta_{\mathrm{e}}\right)$ and aileron $\left(\delta_{\mathrm{a}}\right)$ along with the rudder $\left(\delta_{\mathrm{r}}\right)$ are used as the airframe control inputs in the design model. Only 3 RCS areas, AQR, AYR and ARR, are used as RCS control inputs in the linear design model whereas the "pseudo-nonlinear" model has 5 controlled RCS areas. The reasons for this are that the nose pitch RCS and the two yaw 
RCS thrusters provide thrust in only one direction, and the wing tip roll RCS thrusters are to be used differentially for roll control. For instance yaw RCS thrusters provide only forward thrust, so left yaw RCS is used for right yaw and right yaw RCS is used for left yaw in the actual ("pseudo-nonlinear") model. Using both left and right yaw RCS areas as control inputs in the design model can result in a control design that uses the two areas differentially to enhance yaw control which is inconsistent with the actual implementation. Similar details for pitch and roll RCS area selections, and discussion of RCS distribution logic that distributes the three design model commanded areas to the five actual areas are available in Ref. [16].

The control inputs, WF, A8, ETA, A78, ANG8 and ANG79 in the vector $\bar{u}$, are the propulsion system inputs. The ejector butterfly valve (ETA) controls the engine airflow to the ejectors, thus providing a means of controlling ejector thrust. There are separate control valves for the left and right ejectors, however the two valve angles are set to be equal in the aircraft simulation because no test data is available on the differential use of the ejectors for roll control. Therefore only one butterfly valve angle is used as the control input in the design model. The other five propulsion system control inputs in the design model were just as defined in the full cycle-deck engine simulation.

The flight phase considered in this study is the decelerating transition during approach to hover landing. This phase is representative of low speed, high angle of attack flight and presents a challenging control design problem because the control of the aircraft is transitioning from aerodynamically generated forces and moments to those generated by the propulsion system. For this study, the trimmed "pseudo-nonlinear" and linear design models were obtained for a flight condition with $\mathrm{V}=80$ Knots, flight path angle $\gamma=-3$ deg, angle of attack $\alpha=10 \mathrm{deg}$, and propulsive lift supporting around $60 \%$ of the aircraft weight with adequate distribution between ejector and ventral nozzle thrust to provide pitch trim. The eigenvalues of the linear model for this flight condition are listed in Table 1 and the airframe modes are identified in terms of their "classical" interpretation [18]. As 
seen from Table 1, the design model has an unstable short period mode. The design model responses were compared with the "pseudo-nonlinear" model responses to evaluate model fidelity. An example comparison of pitch rate response to step elevator input is shown in Fig. 3. All the major input-output pair response comparisons showed a good match as in Fig. 3.

\section{$\mathbf{H}_{\mathbf{w}}$ Control Design}

\section{Design Methodology}

The standard $\mathrm{H}_{\infty}$ control design problem, shown in Fig. 4, consists of finding the controller $K(s)$ which will generate control inputs, $\bar{u}$, based on measurements, $\bar{y}$, such that the plant $G(s)$ is stabilized and the infinity norm $\|\cdot\|_{\infty}$ of the response of the controlled variables, $\bar{z}$, to exogenous inputs, $\bar{w}$, is minimized. The IFPC design problem discussed earlier was formulated as a command tracking problem within the framework of Fig. 4 . The detailed block diagram for the $\mathrm{H}_{\infty}$ formulation of the IFPC feedback control design is shown in Fig. 5. The three transfer functions that are of interest for such a problem are the sensitivity function $S(s)$, the complementary sensitivity function $T(s)$, and the control transmission function $\mathrm{C}(\mathrm{s})$. These represent the closed-loop transfers from the reference commands (and disturbances) to tracking errors, controlled variables and commanded control inputs, respectively, i.e. $\overline{\mathrm{e}}=\mathrm{S}(\mathrm{s}) \overline{\mathrm{z}}_{\mathrm{c}}, \overline{\mathrm{z}}=\mathrm{T}(\mathrm{s}) \overline{\mathrm{z}}_{\mathrm{c}}$ and $\overline{\mathrm{u}}=\mathrm{C}(\mathrm{s}) \overline{\mathrm{z}}_{\mathrm{c}}$. In order to influence both the low-frequency and high-frequency properties of the closed-loop system it is desirable to find a controller $\mathrm{K}(\mathrm{s})$ which minimizes a weighted norm of a combination of these three transfer functions, i.e.

$$
\min \|H(j \omega)\|_{\infty} \text { with } H(j \omega)=\left[\begin{array}{l}
W_{S}(j \omega) \cdot S(j \omega) \\
W_{T}^{(j \omega) \cdot T(j \omega)} \\
W_{C}^{(j \omega) \cdot C(j \omega)}
\end{array}\right]
$$

Note that $\|\mathrm{H}(\mathrm{j} \omega)\|_{\infty}$ is the highest value over all frequencies $\omega$ of the maximum singular value of $\mathrm{H}(\mathrm{j} \omega)(\bar{\sigma}[\mathrm{H}(\mathrm{j} \omega)])$.

The weighting functions $\mathrm{W}_{\mathrm{S}}, \mathrm{W}_{\mathrm{T}}$, and $\mathrm{W}_{\mathrm{C}}(\mathrm{j} \omega)$ are the "knobs" used by the control 
designer to "tune" the controller $\mathrm{K}(\mathrm{s})$ such that the design objectives are met. For instance choosing $W_{S}$ to be large at low frequency ensures good command tracking performance and choosing $W_{\mathrm{T}}$ to be large at high frequencies ensures robustness to high frequency unmodelled dynamics. $W_{C}$ are chosen to ensure that control actuation bandwidths and rate and deflections limits are not exceeded in the control design.

The $\mathrm{H}_{\mathrm{w}}$ tracking formulation of Fig. 5 allows for feedback of plant measurements other than just tracking errors as inputs to the controller. This formulation then allows the simultaneous design of inner loop plant augmentation (stability or response shaping) and command tracking system. Plant augmentation is an integral part of flight control design since the overall objective is to design a system for desired piloted handling qualities and not just an automatic command tracking system. Conversely, as pointed out in Ref.[3], ad-hoc procedures have to be used for plant augmentation when LQG/LTR control synthesis technique is used. Also, meaningful application of the LQG/LTR synthesis technique requires the design plant to be square whereas there is no such restriction in the $\mathrm{H}_{\infty}$ control formulation. Some other weaknesses of loop shaping techniques are discussed in Ref. [19]. These are the reasons why $\mathrm{H}_{\infty}$ control synthesis approach was selected to address the feedback control design portion of IMPAC.

\section{Design Specifications}

The vectors $\overline{\mathrm{u}}$ and $\overline{\mathrm{y}}$ in Fig. 5 are the integrated design model inputs and outputs, respectively, as discussed in the previous section. For control design the heading and altitude modes (see Table 1.) were truncated from the design model since these have insignificant contribution to the controlled dynamics. The controlled variables $\bar{z}$ were selected to be

$$
\bar{z}=\left[V_{v}, Q v, h d o t, P v, r, N 2\right]^{T}
$$

with $V_{v}=V d o t+0.1 V, Q v=q+0.3 \theta, P v=p+0.1 \phi$ and the others as discussed under plant outputs. This blending of controlled variables was chosen to provide the response types that are desirable for good handling qualities $[20,21]$ in transition flight. The choice of $V_{v}$ 
corresponds to designing an acceleration (deceleration) command system with velocity hold, and the choice of $\mathrm{Qv}$ and $\mathrm{Pv}$ correspond to designing a rate command-attitude hold system. The break frequencies for switching from rate to attitude command for the case of $\mathrm{Qv}$ and $\mathrm{Pv}$, and from acceleration to velocity command for the case of $\mathrm{Vv}$, were chosen based on open-loop control effectiveness studies. For instance, the elevator $(\delta)$ is effective in pitch rate control in the frequency range of $0.3 \mathrm{rads} / \mathrm{s}$ to $10 \mathrm{rads} / \mathrm{s}$ and is effective in pitch attitude $(\theta)$ control for frequencies below $0.3 \mathrm{rads} / \mathrm{s}$. The choice of hdot in $\overline{\mathrm{z}}$ provides for flight path angle control and the choice of N2 provides for tracking the fan speed commands generated by the engine operating schedule logic. Designing the feedback controller $\mathrm{K}(\mathrm{s})$ to provide decoupled command tracking of the individual elements of $\bar{z}$ will result in a system that provides independent control of acceleration, pitch, flight path angle, roll and yaw (or sideslip) from the various pilot control effectors such as stick, throttle and rudder pedals etc., thus reducing pilot workload.

From the point of reduced pilot workload, it is also desirable to provide automatic turn coordination from the pilot lateral control stick input. To build this turn coordination into the $H_{\omega}$ control synthesis formulation, the yaw rate command $\left(r_{c}\right)$ to be tracked was formulated as

$$
\mathrm{r}_{\mathrm{c}}=\mathrm{r}_{\mathrm{c} 1}+\mathrm{K}_{\phi}^{\mathrm{r}} \phi
$$

where $r_{c 1}$ is the exogenous yaw rate command which the pilot may generate through the rudder pedals to command heading $(\psi)$ or sideslip $(\beta)$, and the second term in (6) represents the yaw rate required for a coordinated turn in response to pilot generated roll rate/attitude commands. The yaw rate for a coordinated turn is given by (see Ref. [18])

$$
r=\frac{V}{g} \tan (\phi)
$$

where $\mathrm{g}$ is the acceleration due to gravity. For small bank angle $\phi, \mathrm{K}_{\phi}^{\mathrm{r}}=.237 \mathrm{deg}-\mathrm{s}^{-1} / \mathrm{deg}$ in (7) will provide the mechanism for building-in turn coordination in the $\mathrm{H}_{\infty}$ control design for the 80 Knot design model. 


\section{Control Design}

The design plant inputs and controlled outputs were normalized by maximum allowable deflections $\left(\bar{u}_{\max }\right)$ and maximum commanded values to be tracked $\left(\bar{z}_{c_{\max }}\right)$ respectively. The $\bar{u}_{\max }$ were chosen to be reasonable deviations from the nominal (trim) values such that the total control deflection limits (as incorporated in the actuator models in the "pseudo-nonlinear" model) will not be exceeded. The $\bar{z}_{\mathbf{c}_{\max }}$ were chosen based on handling qualities control requirements and open-loop control effectiveness analysis of the design plant to ensure that each element of $\bar{z}$ can be commanded individually to its maximum value within its frequency range of interest without exceeding $\bar{u}_{\max }$ value for any of the control inputs. The singular values of the scaled design plant for the 6 controlled variables defined in eqn. (5) are shown in Fig. 6 . The fact that the minimum singular value in Fig. 6 is less than 1 implies that there exist combinations of numerical values of commands $\bar{z}_{c}$ such that although each element of $\bar{z}_{c}$ is less than its maximum value, the combined commands $\bar{z}_{c}$ cannot be tracked without exceeding the control limits $\bar{u}_{\max }$ for some control input.

The sensitivity weights $\mathrm{W}_{\mathrm{S}}$ and the complementary sensitivity weights $\mathrm{W}_{\mathrm{T}}$ for each of the controlled variables were chosen to be first-order, to provide adequate frequency response shaping without overly increasing the resulting controller order. The $\mathrm{W}_{\mathrm{S}}$ zero and pole for each controlled variable were chosen to result in a low frequency gain of 100 , gain crossover frequency of 1.5 times the desired tracking bandwidth for the variable and a high frequency gain of 0.1. The $\mathrm{W}_{\mathrm{T}}$ were chosen to obtain a low frequency gain of 0 , gain crossover frequency of 1.8 times the desired tracking bandwidth, and a high frequency gain of 100. The reasons for these choices are as discussed in the design methodology section. Note that, in general, a higher value of low frequency $W_{S}$ gain is used to build-in integral control action to provide "perfect" steady-state tracking of step commands. The "pure" integral control action is really not necessary in the piloted flight control problem because the pilot is closing the outer loop. The pilot can easily be trained to compensate for "small" steady-state offsets without excessive workload. It was felt that a low frequency $W_{S}$ gain 
of 100 will be "large" enough to result in a controller that provides steady-state tracking of step commands with "small" errors.

The desired tracking bandwidths for all the commanded variables are listed in Table 2. These were chosen based on handling qualities requirements and open-loop analysis of the design plant to determine maximum control bandwidth for each commanded variable using all the control inputs $\bar{u}$. The weights $W_{S}$ and $W_{T}$ for the $Q v$ commanded variable are shown in Fig. 7 as an example.

Initially only the control inputs $\bar{u}$ were weighted in the control design with $\mathrm{W}_{\mathbf{u}}$ in Fig. 5 chosen to be the inverse of $\bar{u}_{\max }$ for each control input. However this resulted in a control design with large control rates. Therefore it was decided to weight the control rates also in the $\mathrm{H}_{\mathbf{w}}$ design with $\mathrm{W}_{\dot{u}}$ chosen to be the inverse of maximum control rates. Since using full order actuator models for each control input would have resulted in a very high-order controller, first order actuator approximations were used in the control design. Describing function analysis [22] of the full order actuators was first performed to determine the degradation in actuator bandwidth due to rate limiting when control commands corresponding to $\bar{u}_{\max }$ are used at all frequencies. The worst-case rate-limited actuator bandwidth was then used as the bandwidth for first-order design actuators. For example, the pitch RCS area actuator bandwidth is $20 \mathrm{rad} / \mathrm{s}$ but the rate limit is $3.0 \mathrm{in}^{2} / \mathrm{s}$ which results in a worst case bandwidth of $6.0 \mathrm{rad} / \mathrm{s}$ for $A Q R_{\max }$ of $0.7 \mathrm{in}^{2}$. Although this conservatism in design actuator bandwidth selection might result in limiting nominal performance to below what is achievable, it should provide robustness to non-linearities due to actuator rate limiting.

The design plant as discussed above is of 37 th order consisting of the 13th order integrated aircraft design model, first order actuators for the 12 control inputs, and first order sensitivity and complementary sensitivity weights for the 6 controlled variables. So the $\mathrm{H}_{w}$ controller using the algorithm of Ref. [5] will be of 37 th order. The $\mathrm{H}_{\infty}$ control design results with this design plant set-up are shown in Fig. 8 in terms of the closed loop 
maximum singular values of the combined weighted functions $\bar{\sigma}[\mathrm{H}(\mathrm{j} \omega)]$, weighted errors $\bar{\sigma}\left[\mathrm{W}_{\mathrm{S}} \overline{\mathrm{e}}(\mathrm{j} \omega)\right]$, weighted controlled outputs $\bar{\sigma}\left[\mathrm{W}_{\mathrm{T}} \overline{\mathrm{z}}(\mathrm{j} \omega)\right]$, weighted controls $\bar{\sigma}\left[\mathrm{W}_{\mathrm{u}} \overline{\mathrm{u}}(\mathrm{j} \omega)\right]$, and weighted control rates $\bar{\sigma}\left[\mathrm{W}_{\dot{\mathrm{u}}} \dot{\overline{\mathrm{u}}}(\mathrm{j} \omega)\right]$ with the commands $\overline{\mathrm{z}}_{\mathrm{c}}$ as inputs. $\|\mathrm{H}(\mathrm{j} \omega)\|_{\infty}=10$ is achieved for this controller as seen from Fig. 8. In general a control design with $\|H(j \omega)\|_{\infty} \leq$ 1 ensures that all the design specifications that are formulated through the various weightings will be met. However, this was not the case in the present design, because as stated earlier the minimum singular value of the scaled design plant itself was much less than 1. The fact that control efforts greater than $\overline{\mathbf{u}}_{\max }$ will be required to track some combinations of commands is evident from the large $(>1)$ maximum singular values of weighted controls at low frequencies. The fact that maximum singular value of weighted errors is greater than 1 at low frequencies indicates the performance/control trade-off made in the $\mathrm{H}_{\omega}$ minimization procedure. The fact that the maximum singular values of the weighted controlled outputs and control rates are less than 1 over all frequencies indicates that the $\mathrm{H}_{\infty}$ controller provides adequate "loop gain" roll-off for the closed-loop system to be robust to unmodelled high frequency dynamics and that the control rate limits will not be exceeded for any combinations of commanded variables.

The $\mathrm{H}_{\mathrm{w}}$ controller resulted in a stable closed-loop system for the design plant with the $\psi$ and h states included. The controller itself was stable, as seen from the eigenvalues listed in Table 3., and had no transmission zeros. In Ref. [23] it is shown that if a tracking problem is formulated within the $\mathrm{H}_{\infty}$ framework as purely a servo-mechanism problem, i.e. with controller inputs being just the tracking errors, then the $\mathrm{H}_{\infty}$ controller will be such that its transmission zeros cancel the stable poles of the design plant resulting in a closed-loop system that will be guaranteed to have almost no robustness to plant modelling uncertainties. Clearly then, formulating the $\mathrm{H}_{\infty}$ control problem as a combined plant augmentation and tracking problem, as is the case in this study (see Fig. 5 and previous discussion), also gets around the lack of robustness issue. Further evaluation 
results for the $\mathrm{H}_{\mathrm{w}}$ controller are presented in the next section in conjunction with results for a reduced-order controller.

\section{Controller Reduction and Evaluation}

A 23rd order and a 21st order controller were obtained by first putting the $\mathrm{H}_{\infty}$ controller in modal form and then residualizing the "fast" actuator modes -24 . to 37 and 22 to 37 , respectively, in Table 3 . Note that the objective of controller reduction here was not to get the "optimal" (least) order controller that gives desired performance, but to see whether the "fast" controller modes which come about mainly due to the complementary sensitivity weighting poles in the design plant can be "removed" from the controller without any significant loss in closed-loop performance. The 23rd order reduced controller maximum and minimum singular values, $\bar{\sigma}\left[\mathrm{K}_{\mathrm{r}}(\mathrm{j} \omega)\right]$ and $\underline{\sigma}\left[\mathrm{K}_{\mathrm{r}}(\mathrm{j} \omega)\right]$, are compared with the $H_{\infty}$ controller singular values, $\bar{\sigma}[K(j \omega)]$ and $\underline{\sigma}[\mathrm{K}(\mathrm{j} \omega)]$, in Fig. 9. This reduced-order controller provides a good match to the $\mathrm{H}_{\infty}$ controller up to $20 \mathrm{rad} / \mathrm{s}$ which is nearly a decade above the maximum of the desired command tracking bandwidths (from Table 2.). The 21st order reduced controller did not provide such a good match in the frequency region of interest, so this controller is not discussed any further. The frequency responses of the closed-loop system, with linear design model and no actuators, were also compared for the reduced (23rd order) and full-order controllers. An example comparison for Qv response to $\mathrm{Qv}$ is shown in Fig. 10. All other response comparisons were equally as good as the one in Fig. 10 indicating that there will be no loss in closed-loop performance when the 23rd order controller is used in place of the 37 th order $\mathrm{H}_{\infty}$ controller. In the rest of the paper all the evaluation results are discussed with reference to the reduced order controller.

Extensive frequency-domain and time-domain analyses were performed to evaluate the closed-loop performance with the linear design model. An example of the frequency-domain results is shown in Fig. 11. and an example of the time-domain results is shown in Fig. 12. Fig. 11 shows the Bode plots for closed-loop response of Qv, Vv, hdot and $\mathrm{Pv}$ to $\mathrm{Qv}$ command. The controller provides decoupling of the longitudinal responses 
at low frequencies and good tracking of the steady-state commands. However, the bandwidth for tracking $Q v$ commands is only $1.8 \mathrm{rad} / \mathrm{s}$ whereas a bandwidth of $2.24 \mathrm{rad} / \mathrm{s}$ was specified in the control design. Here bandwidth is defined as the frequency for which the closed-loop gain for the commanded variable is $-3 \mathrm{~dB}$. The achieved tracking bandwidths for all the commanded variables are listed in Table 2 which shows lower than specified bandwidths for all the longitudinal variables. The reasons for this will be discussed later in this paper. The increased coupling from $Q v_{c}$ to $V v$ and hdot in the mid frequency region, 0.5 to $1.0 \mathrm{rad} / \mathrm{s}$, as seen from Fig. 11, is clearly due to the low tracking (regulating) bandwidths achieved for these variables. The coupling from $\mathrm{Qv}_{\mathrm{c}}$ to lateral response $(\mathrm{Pv})$ around $2 \mathrm{rad} / \mathrm{s}$ is due to the excitation of the dutch roll mode. Although there is no coupling from the longitudinal control effectors, such as $\delta$, AQR etc., to the lateral responses in the open-loop design model, the $\mathrm{H}_{\infty}$ controller was such that the yaw RCS, AYR, was used for acceleration/velocity control resulting in the excitation of the lateral/directional modes from longitudinal commands. The directional variable ( $\mathrm{r}$ ) and engine fan speed (N2) responses to Qv command were very small indicating decoupling of these responses from longitudinal commands. The $\mathrm{r}$ and $\mathrm{N} 2$ frequency responses are not shown in Fig. 11 to avoid cluttering the figure.

The closed-loop frequency responses to other longitudinal commands, $V_{v_{c}}$ and hdot $_{c}$, showed similar characteristics as for the $Q v_{c}$. The fan speed response was decoupled from both longitudinal and lateral commands and perfect tracking of fan speed commands was achieved with desired bandwidth. There was very little coupling from the lateral commands to longitudinal responses, and although the open-loop dutch-roll mode was also a closed-loop eigenvalue, this mode was "notched" out in the lateral/directional (Pv and r) response to respective commands. This notch filter effect of the controller is also evident from the minimum singular value of the controller plotted in Fig. 9. The dutch-roll mode frequency and damping were within Level I handling qualities boundary [20], and furthermore a desired controller structure, such as making controller transmission from $e_{V v}$ 
(Vv tracking error) to AYR to be 0 , can always be imposed in controller partitioning and simplification. So, the coupling from longitudinal commands to lateral responses might not be of great concern for this controller design.

The time-response of the closed-loop system to step $\mathrm{Pv}_{\mathrm{c}}$ is shown in Fig. 12 to demonstrate the achieved turn coordination. The $\mathrm{Pv}_{\mathrm{c}}$ was generated to command transient roll rate $p_{c}$ and steady-state roll attitude $\phi_{c}$. The roll rate command is tracked with a rise time of 1.2 secs and the attitude command is adequately tracked with a small lag. The steady-state offset in tracking $\phi_{c}$ is mainly due to the fact that $\phi_{c}$ was generated by integrating the body axis roll rate command $\mathrm{p}_{\mathrm{c}}$ whereas the controlled variable $\phi$ is the Euler bank angle. The yaw rate response shows good tracking of the yaw rate command generated for turn coordination. In the sideslip $(\beta)$ response plot, the solid line corresponds to $\beta$ with turn coordination gain $\mathrm{K}_{\phi}^{\mathrm{T}}$ used in controller design and the dashed line corresponds to $\beta$ with the turn coordination gain made zero in the simulation. The designed controller clearly achieves a high degree of turn coordination and will result in considerable reduction in pilot workload for this task.

Note that in actual implementation of an integrated flight propulsion control system, the engine fan speed N2 will be scheduled with commanded thrust. Since the longitudinal dynamics of the aircraft are strongly coupled, tracking pitch rate and flight path angle commands ( $Q v$ and hdot respectively) with no acceleration variable $\mathrm{Vv}$ command, or commanding $\mathrm{Vv}$ with other variables being regulated will require transient changes in the engine operating point. So the $\mathrm{H}_{\infty}$ control design specification of decoupled command tracking of engine fan speed N2 and the longitudinal control variables Vv, Qv, and hdot is not consistent with the "physics" of the integrated system. This is the reason why the desired command tracking bandwidths were not achieved for the longitudinal controlled variables as per discussion of Table 2. results earlier. This coupling between acceleration command and engine operating point schedule should clearly be taken into account in the feedback control problem formulation for the resulting IFPC design to be 
meaningful. Techniques for incorporating this coupling within the $\mathrm{H}_{w}$ control design procedure are currently being investigated.

Closed-loop simulations using the "pseudo-nonlinear" integrated model were performed to evaluate the performance of the designed controller in the presence of engine, airframe and RCS actuators and associated nonlinearities. An example result for response to step pitch rate variable (Qv) command is shown in Fig. 13. The Qv command was generated to command transient pitch rate and steady-state pitch attitude. Shown in Fig. 13 are the pitch rate, attitude, and fan speed as well as the required RCS bleed flow with both the linear design model and the "pseudo-nonlinear" evaluation model. The controlled performance with the "pseudo-nonlinear" model is quite comparable to that with the linear design model in terms of tracking pitch rate commands up to 1.2 secs. However, beyond that time the controller does not do as good a job of tracking the command with the "pseudo-nonlinear" model as it does with the linear model. The reasons for this can be understood by analyzing the corresponding fan speed regulation errors and bleed flow requirements. In the design model, the relationship from RCS commanded areas to bleed flows is linear i.e. negative areas (RCS thrust in the negative direction) result in negative bleed flow. So, as seen from Fig. 13, the $\mathrm{H}_{\infty}$ controller is such that it results in negative bleed flow i.e. it uses RCS thrusts to control aircraft attitudes and angular rates while "pumping" air into the engine to regulate fan speed. In reality the bleed flow demand will be positive regardless of the direction of the commanded RCS thrust (area). This is the logic implemented in the "pseudo-nonlinear" model and as seen from Fig. 13, the large positive bleed flow demand acts as a disturbance on the engine resulting in large fan speed deviations from the nominal. Once the fan speed error becomes significant, the controller emphasizes fan speed regulation at the expense of pitch rate tracking.

Clearly, a more "intelligent" approach needs to be taken for IFPC design in the presence of absolute RCS nonlinearities. One approach that is currently under investigation is to remove the interaction from the RCS commanded thrusts (areas) via bleed flow to the 
engine in the design model, and design the $\mathrm{H}_{\infty}$ controller for tracking engine fan speed and aircraft attitude commands in the presence of compressor bleed flow disturbance. Also, the large steady-state errors in tracking pitch attitude command with the "pseudo-nonlinear" model, as seen from Fig. 13, indicate that a larger value of the sensitivity weighting should be chosen at low frequencies to ensure integral control action in the presence of low frequency modelling errors.

\section{Conclusions}

The Integrated Flight/Propulsion Control (IFPC) system design presented in this paper demonstrates the applicability of $\mathrm{H}_{\infty}$ control synthesis technique to integrated control design for complex systems such as Short Take-Off and Vertical Landing (STOVL) aircraft. The strength of $\mathrm{H}_{\infty}$ control design is in the ability to address closed-loop performance, robustness and control actuation trade-offs within an integrated framework in the frequency domain. Also, the $\mathrm{H}_{\infty}$ formulation allows for synthesis of inner-loop plant augmentation which offers a distinct advantage over loop shaping techniques when applied to flight control. However, as demonstrated by this example study, knowledge of the "physics of the system" coupled with "classical" control designers' intuition are essential to a meaningful problem formulation within the $\mathrm{H}_{\infty}$ framework. The high-order of the $\mathrm{H}_{\infty}$ controller did not pose a problem in this study because the "fast" controller modes could be residualized without any loss in closed-loop performance.

The controller designed in this study provides decoupled tracking of longitudinal, lateral and engine fan speed commands for a STOVL aircraft in the transition flight phase. A procedure for providing automatic turn coordination within the $\mathrm{H}_{\infty}$ framework was developed and demonstrated. Adequate tracking bandwidths were achieved for the lateral/directional (roll rate and yaw rate) and engine fan speed commands. The achieved bandwidths for the longitudinal (acceleration, pitch rate and flight path angle) were lower than specified because of the design specification of decoupled command tracking for fan speed and longitudinal variables. Design procedures which incorporate the engine fan speed 
schedule based on acceleration command within the synthesis formulation are currently being investigated. Closed-loop evaluation of the controller with a "pseudo-nonlinear" model, which consists of the full-order actuators and associated deflection and rate limit nonlinearities, showed deterioration in performance as compared to the closed-loop system performance for the linear design model. The reason for this deterioration in performance is the absolute nonlinearity from the reaction control system (RCS) thruster commanded areas to the compressor bleed flow demand. Procedures for formulating the design model such that the RCS bleed flow nonlinearity is appropriately reflected in the $H_{\infty}$ IFPC synthesis framework are currently being investigated. 


\section{References}

[1] Smith, K.L., "Design Methods for Integrated Control Systems," AFWAL-TR-86-2103, Wright Patterson AFB, OH, December 1986.

[2] Shaw, P.D., Rock, S.M., and Fisk, W.S., "Design Methods for Integrated Control Systems," AFWAL-TR-88-2061, Wright Patterson AFB, OH, June 1988.

[3] Garg, S., Mattern, D.L., and Bullard, R.E., "Integrated Flight/Propulsion Control System Design Based on a Centralized Approach," AIAA Paper 89-3520, Proceedings of the 1989 AIAA Guidance, Navigation and Control Conference, Boston, MA., August 1989, pp. 827-839.

[4] Mattern, D.L., Garg, S., and Bullard, R.E., "Integrated Flight/Propulsion Control System Design Based on a Decentralized, Hierarchical Approach," AIAA Paper 89-3519, presented at the AIAA Guidance, Navigation and Control Conference, Boston, MA, August 1989.

[5] Doyle, J.C., Glover, K., Khargonekar, P.P., and Francis B.A., "State-Space Solutions to Standard $\mathrm{H}_{2}$ and $\mathrm{H}_{\infty}$ Control Problems," IEEE Transactions on Automatic Control, Vol. 34, No. 8, August 1989, pp. 831-847.

[6] Safonov, M.G., Limebeer, D.J.N., and Chiang, R.Y., "Simplifying the $\mathrm{H}_{\infty}$ Theory via Loop-Shifting, Matrix-Pencil and Descriptor Concepts," Int. J. of Control, 1989, Vol. 50, No. 6, pp. 2467-2488.

[7] Schmidt, P.H., Garg, S., and Lorenzo, C.F., "Partitioning Methods for Global Controllers," Proceedings of the 1990 American Control Conference, San Diego, CA, May 1990, pp. 167-168.

[8] Lehtomaki, N.A., Stein, G., and Wall J.E., "Multivariable Prefilter Design for Command Shaping," AIAA Paper 84-1829, Guidance, Navigation and Control Conference, Seattle, WA, August 1984.

[9] "MATRIXx Robust Control Module - User's Guide," Integrated Systems Inc., Santa Clara, CA, October 1989.

[10] Williams, S.J., and Smith P.R., "Comparison of Characteristic Locus and H-Infinity Methods in VSTOL Flight Control System Design," AIAA Paper 89-3491, Proceedings of AIAA Guidance, Navigation and Control Conference, Boston, MA, August 1989, pp. 1065-1072.

[11] Kaminer, I., Khargonekar, P.P., and Robel, G., "Design of Localizer Capture and Track Modes for a Lateral Autopilot Using H-Infinity Synthesis," IEEE Control Systems Magazine, Vol. 10, No. 4, June 1990, pp. 13-21.

[12] Reichert, R., "Application of H-Infinity Control to Missile Autopilot Design," AIAA Paper 89-3550, Proceedings of the AIAA Guidance, Navigation and Control Conference, Boston, MA, August 1989, pp. 1065-1072.

[13] Akhter, M.M., Vincent, J.H., Berg, D.F., and Bodden, D.S., "Simulation 
Development for US/Canada Controls Technology Program," Proceedings of the Twentieth Annual Modeling and Simulation Conference, University of Pittsburgh, Pittsburgh, PA, June 1989.

[14] "E-7D Simulation Math Model Specification," Systems Control Technology, Palo Alto, CA, May 1990.

[15] Adibhatla, S. et al., "GE Aircraft Engines F110 / STOVL Multivariable Propulsion Control," GE internal document, General Electric Aircraft Engines, Cincinnati, $\mathrm{OH}$, August 1989.

[16] Garg, S., et al., "Evaluation and Design Model Development for IMPAC Integrated Methodology for Airframe and Propulsion Control," NASA document under preparation.

[17] Kokotovic, P.V., and Sannvie, P., "Singular Perturbation Method for Reducing Model Error in Optimal Control Design," IEEE Trans. on Automatic Control, AC-13, pp.377-384, 1968.

[18] McRuer, D.T., Ashkenas, I., and Graham, D., "Aircraft Flight Dynamics and Automatic Control," Princeton University Press, 1973.

[19] Stein, G., and Doyle, J.C., "Beyond Singular Values and Loop Shapes," Collection of Notes and Papers for MUSYN Robust Control Short Course, Arcadia, CA, Sept. 1989.

[20] "Military Specification - Flying Qualities of Piloted V/STOL Aircraft," Mil-F-83300, Wright Patterson AFB, OH, December 1970.

[21] Hoh, R.H., and Mitchell, D.G., "Proposed Revisions to MIL-F-83300 V/STOL Flying Qualities Specification," NADC-82146-60, Naval Air Development Center, Warminster, PA, January 1986.

[22] Ogata, K., "Modern Control Engineering," Prentice Hall Inc., 1970.

[23] Chiang, R.Y., Safonov, M.G., and Tekawy, J.A., "H ${ }_{\infty}$ Flight Control Design with Large Parametric Robustness," Proceedings of the 1990 American Control Conference, San Diego, CA, May 1990. 
Table 1. Eigenvalues of Design Model

\begin{tabular}{cc} 
Eigenvalue & Description \\
$-2.1 \mathrm{e}-09$ & Heading Mode \\
$4.7 \mathrm{e}-05$ & Altitude Mode \\
$-8.5 \mathrm{e}-02$ & Spiral Mode \\
$-0.106 \pm j 0.279$ & Phugoid Mode \\
1.294 & Unstable Short Period \\
-1.725 & Roll Mode \\
-2.092 & Stable Short Period \\
$-0.232 \pm \mathrm{j} 2.269$ & Dutch Roll Mode \\
-4.122 & Rotor Speeds \\
-7.109 & Temperatures \\
-29.39 & Pressure Mode \\
-38.21 & \\
-199.7 & \\
\hline
\end{tabular}

Table 2. Command Tracking Bandwidths ( $\omega_{\mathrm{BW}}$ )

\begin{tabular}{ccc} 
Variable & $\begin{array}{c}\text { Desired } \omega_{\mathrm{BW}} \\
(\mathrm{rad} / \mathrm{s})\end{array}$ & $\begin{array}{c}\text { Achieved } \omega_{\mathrm{BW}} \\
(\mathrm{rad} / \mathrm{s})\end{array}$ \\
$\mathrm{Vv}$ & 0.9 & 0.55 \\
$\mathrm{Qv}$ & 2.24 & 1.8 \\
$\mathrm{hdot}$ & 0.8 & 0.5 \\
$\mathrm{Pv}$ & 1.5 & 1.8 \\
$\mathrm{r}$ & 1.5 & 1.8 \\
$\mathrm{~N} 2$ & 2.5 & 2.6 \\
\hline
\end{tabular}


Table 3. H Controller Eigenvalues

\begin{tabular}{|c|c|}
\hline No. & Eigenvalue \\
\hline $\begin{array}{c}1 . \\
2 . \\
3 . \\
4 . \\
5 . \\
6 . \\
7 . \\
8 . \\
9 . \\
10 . \\
11 . \\
12 . \\
13 . \\
14,15 . \\
16 . \\
17 . \\
18,19 . \\
20,21 . \\
22 . \\
23 . \\
24 . \\
25 . \\
26 . \\
27 . \\
28,29 . \\
30 . \\
31 . \\
32 . \\
33 . \\
34 . \\
35 . \\
36 . \\
37 .\end{array}$ & $\begin{array}{c}-3.73 \mathrm{e}-03 \\
-1.19 \mathrm{e}-02 \\
-1.34 \mathrm{e}-02 \\
-2.22 \mathrm{e}-02 \\
-2.24 \mathrm{e}-02 \\
-3.36 \mathrm{e}-02 \\
-4.63 \mathrm{e}-02 \\
-7.58 \mathrm{e}-02 \\
-0.269 \\
-0.713 \\
-1.187 \\
-2.076 \\
-3.205 \\
-3.34 \pm \mathrm{j} 0.47 \\
-4.504 \\
-5.457 \\
-6.63 \pm \mathrm{j} 0.55 \\
-6.98 \pm \mathrm{j} 4.14 \\
-8.353 \\
-8.982 \\
-10.25 \\
-11.91 \\
-12.70 \\
-34.71 \\
-35.53 \pm \mathrm{j} 6.22 \\
-36.74 \\
-179.3 \\
-1.44 \mathrm{e}+03 \\
-2.70 \mathrm{e}+03 \\
-2.70 \mathrm{e}+03 \\
-2.70 \mathrm{e}+03 \\
-4.05 \mathrm{e}+03 \\
-4.50 \mathrm{e}+03\end{array}$ \\
\hline
\end{tabular}




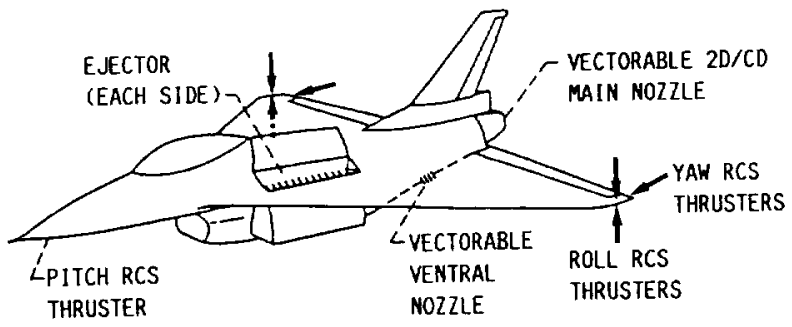

FIGURE 1. - CONTROL EFFECTORS FOR E-7D AIRCRAFT.

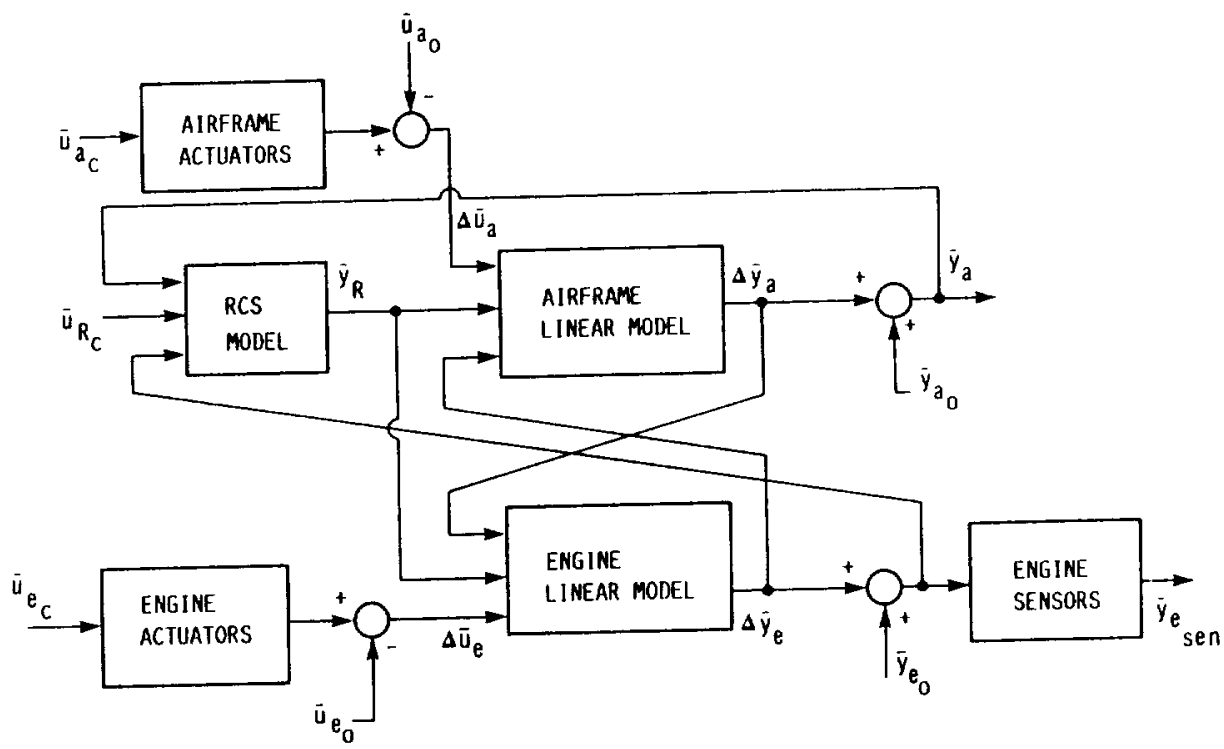

Figure 2. - integrated airframe/Propulsion "PSEUdO-nONL INEAR" MODEL.

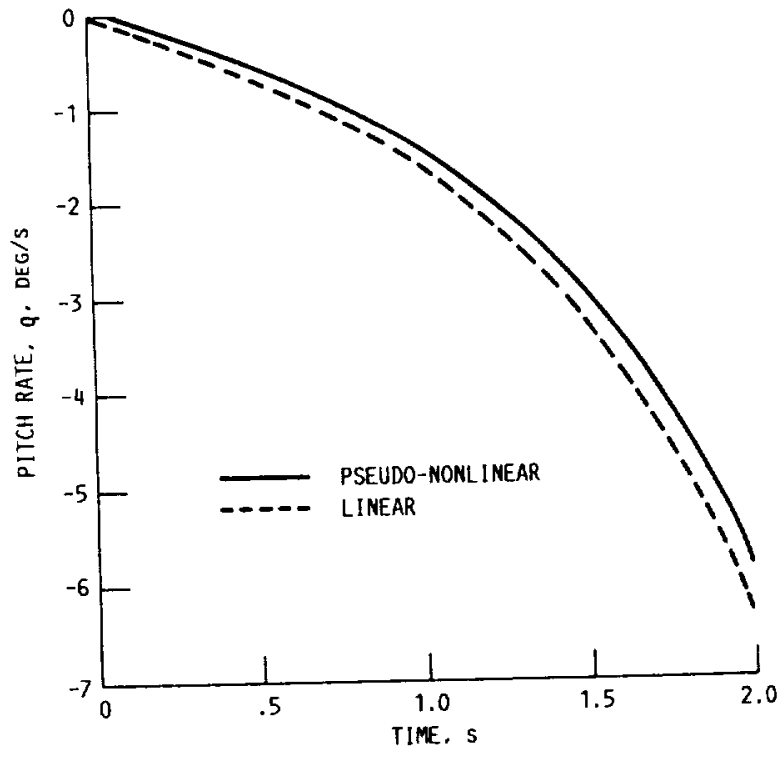

FIGURE 3. - EXAMPLE RESPONSE COMPARISONS FOR LIMEAR AND "PSUEDO-NONL INEAR" MODELS - PITCH RATE (q) RESPONSE TO UNIT STEP ELEVATOR ( $\delta$ e) INPUT.

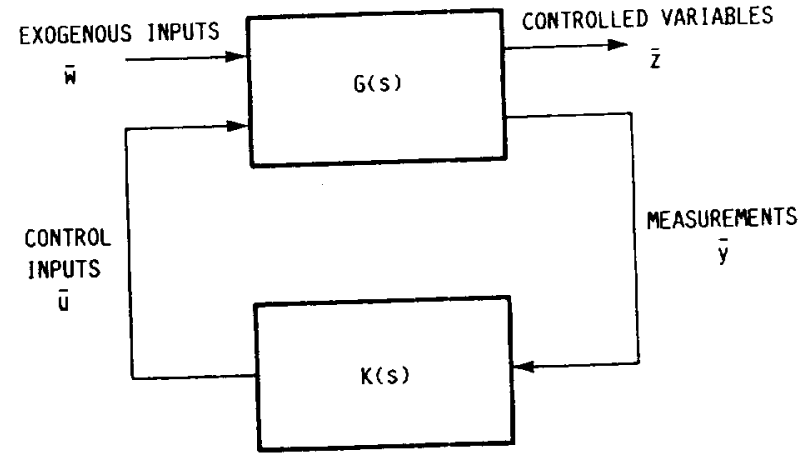

FIND $K(S)$ TO STABILIZE $G(S)$

AND MINIMIZE $\|\overline{\bar{z}} \overline{\bar{w}}\|_{\infty}$

FiguRE 4. - $H_{\infty}$ CONTROL PROBLEM FORMULATION. 


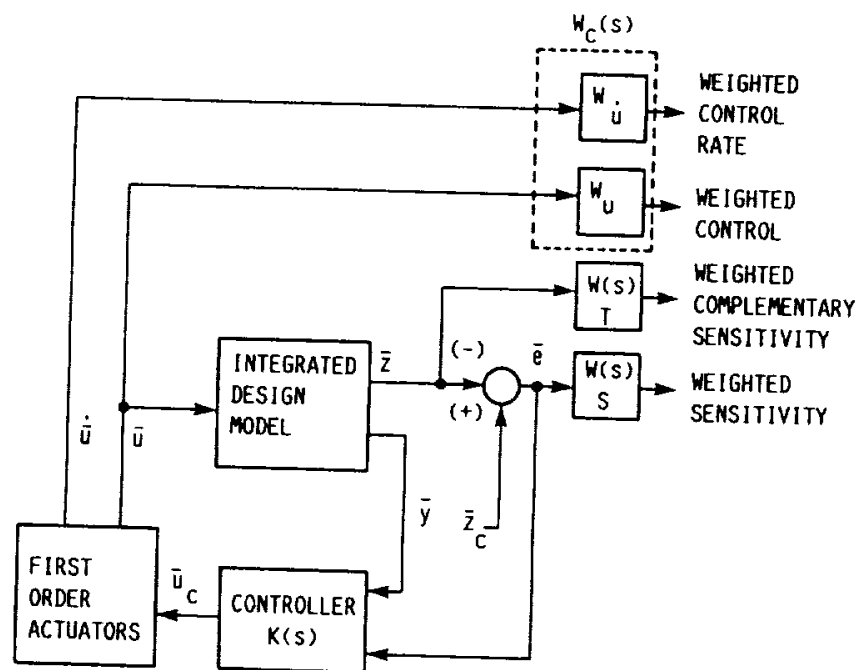

FIGURE 5. - BLOCK DIAGRAM FOR H $_{\infty}$ FORMULATION OF IFPC FEEDBACK
DESIGM.

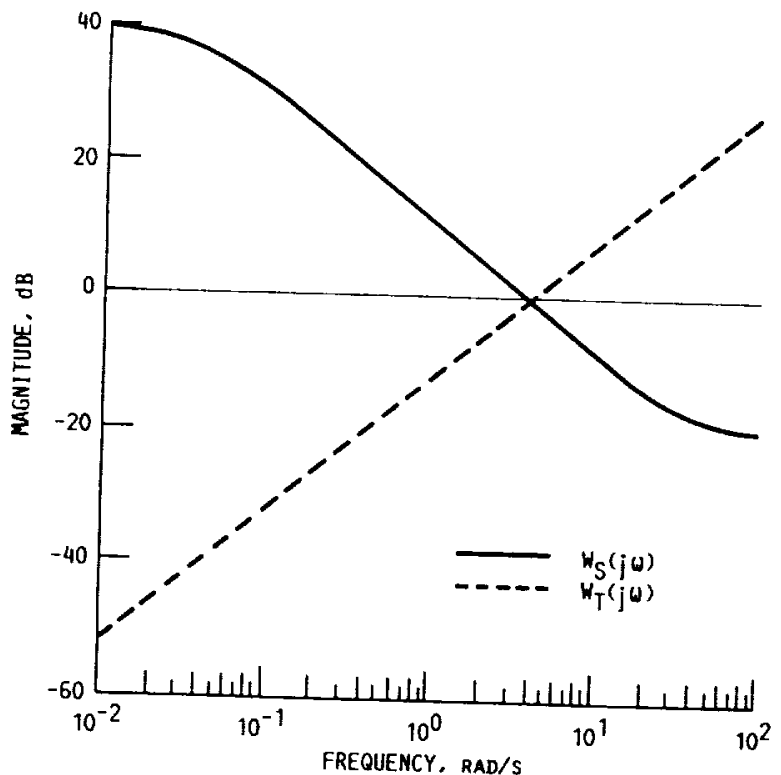

FIGURE 7. - EXAMPLE SENSITIVITY AND COMPLEMENTARY SENSITIVITY WEIGHTS. WS AND $W_{T}$ FOR OV.

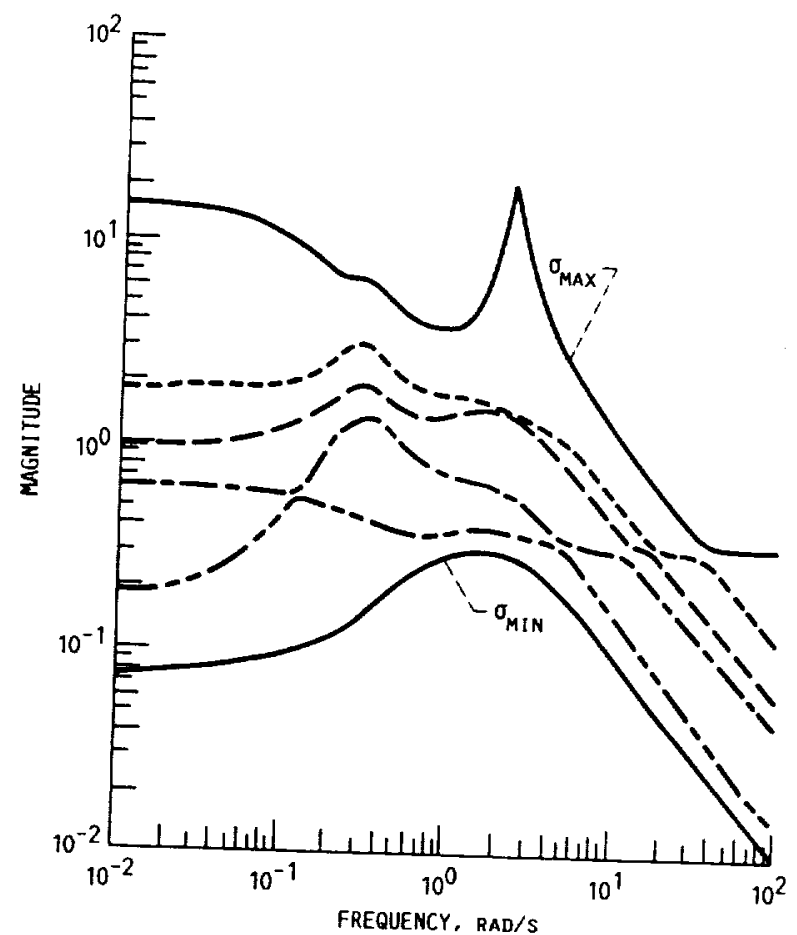

figure 6. - Singular values of SCALEd design plant.

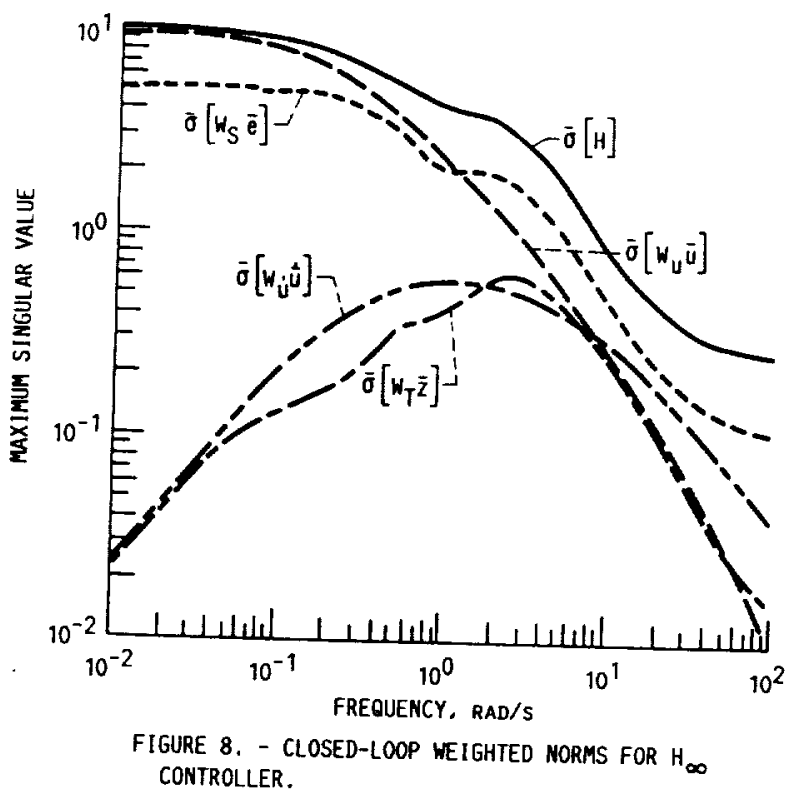

FIGURE 8, - CLOSED-LOOP WEIGHTED NORMS FOR $H_{\infty}$ 

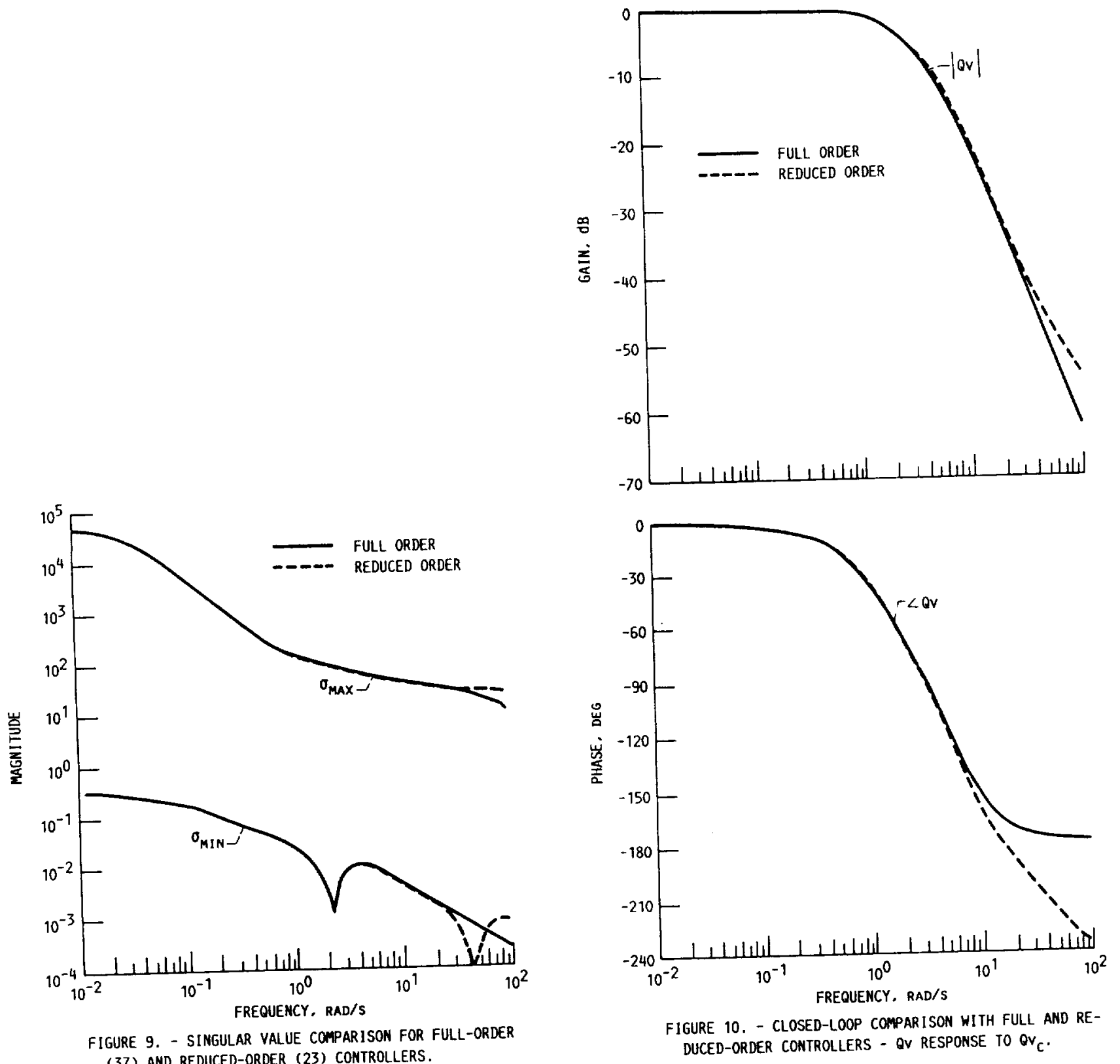

FIGURE 9. - SINGULAR VALUE COMPARISON FOR FULL-ORDER (37) AND REDUCED-ORDER (23) CONTROLLERS. 

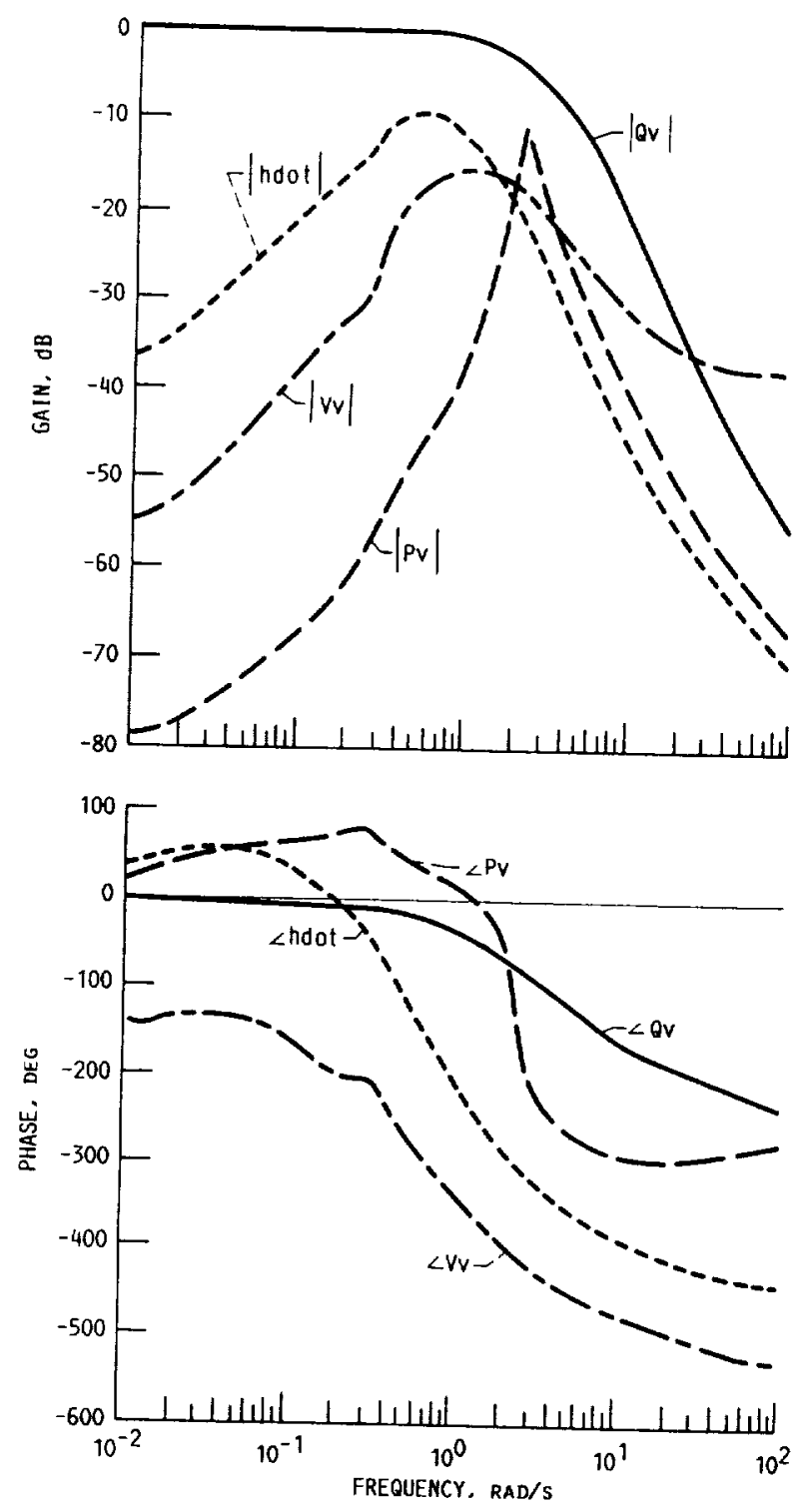

FIGURE 11. - CLOSED-LOOP FREQUENCY RESPONSE TO PITCH RATE VARIABLE COMMAND $\left(\mathrm{OV}_{\mathrm{c}}\right)$. 

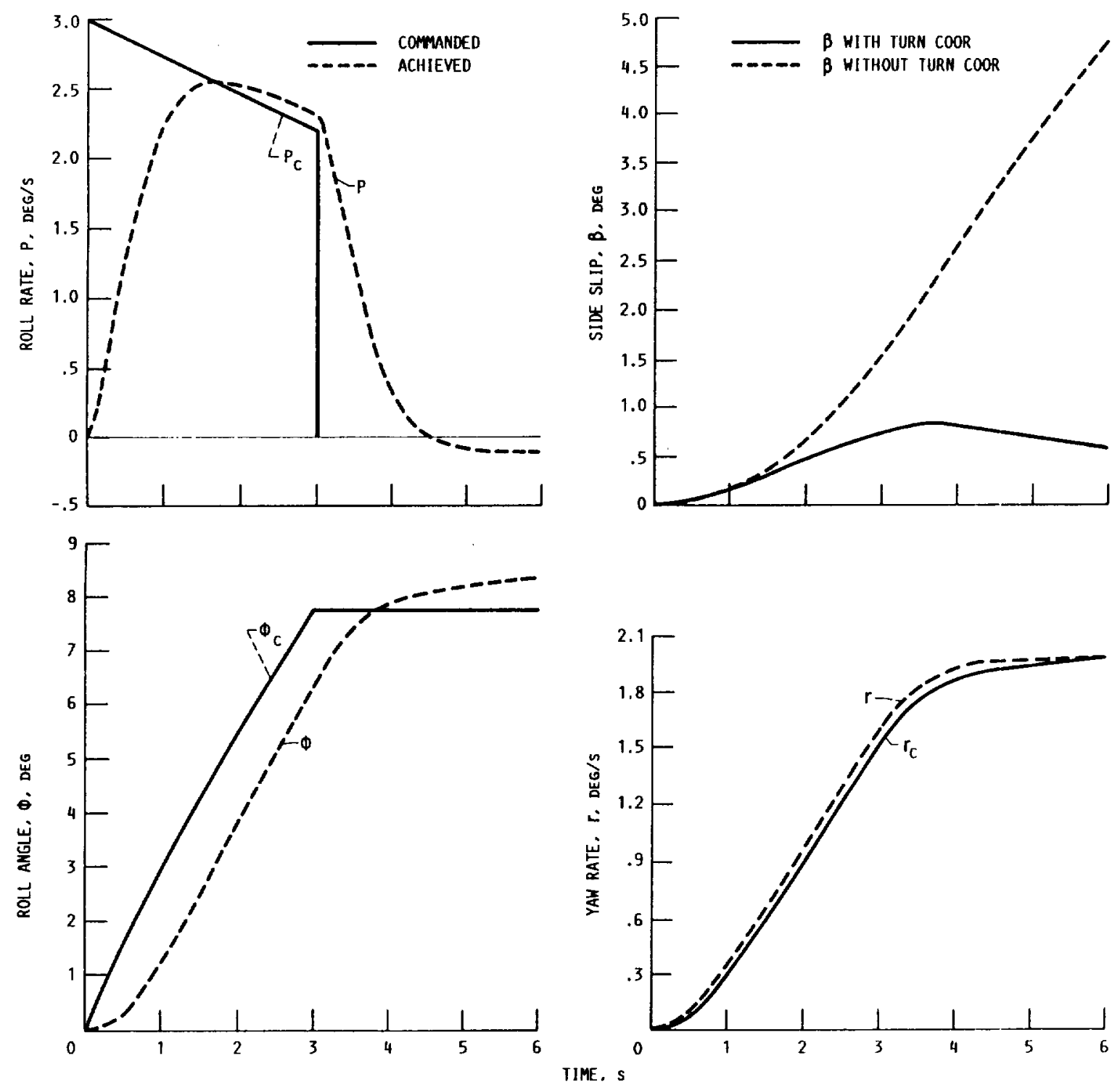

FIGURE 12. - CLOSED-LOOP TIME RESPONSE TO ROLL RATE VARIABLE COMMAND (PV $)$. 

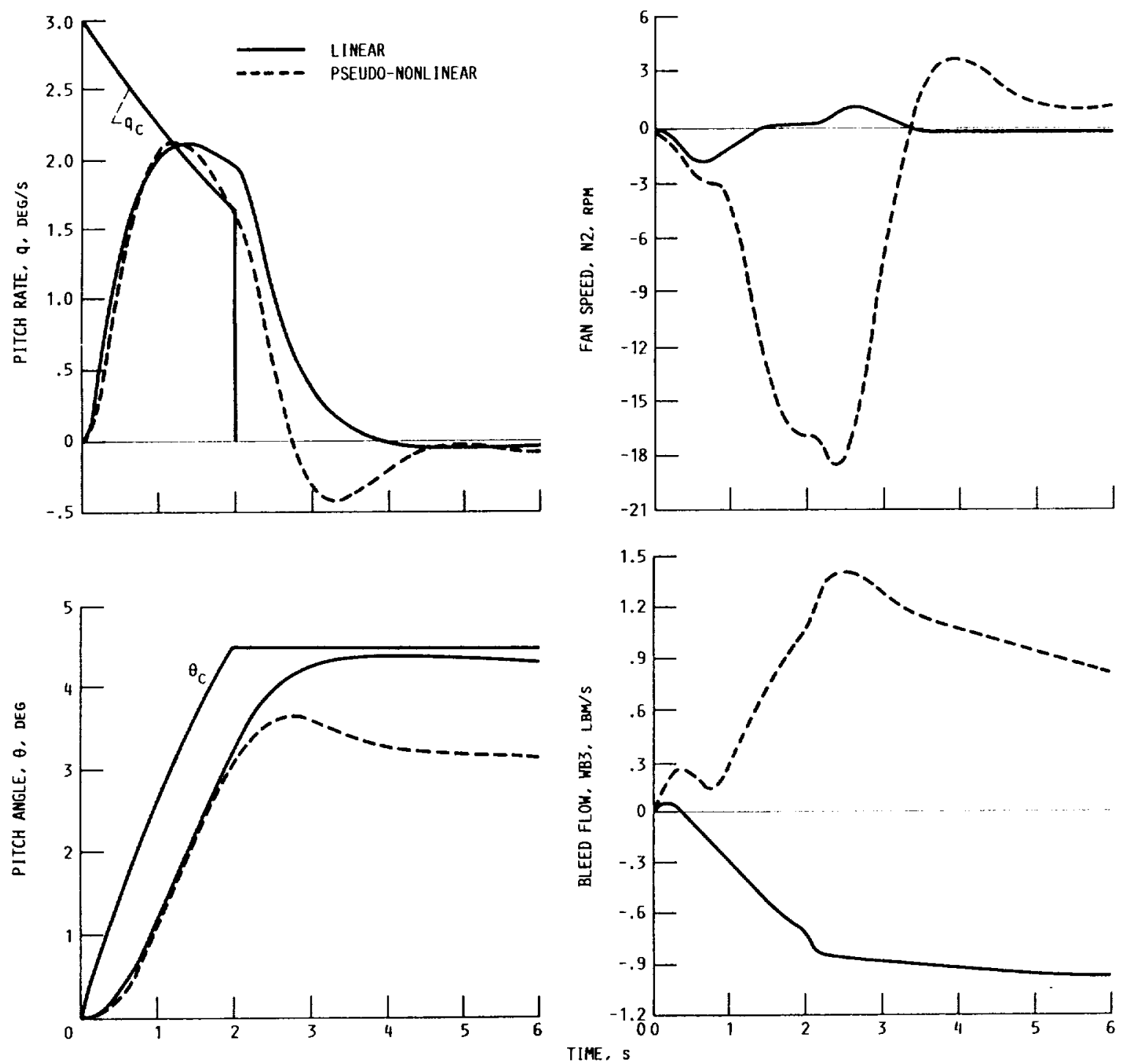

FigURE 13. - EXAMPLE COMPARISON OF CLOSED-LOOP RESPONSE WITH LINEAR AND "PSEUDO-NONL INEAR" MODELS. 


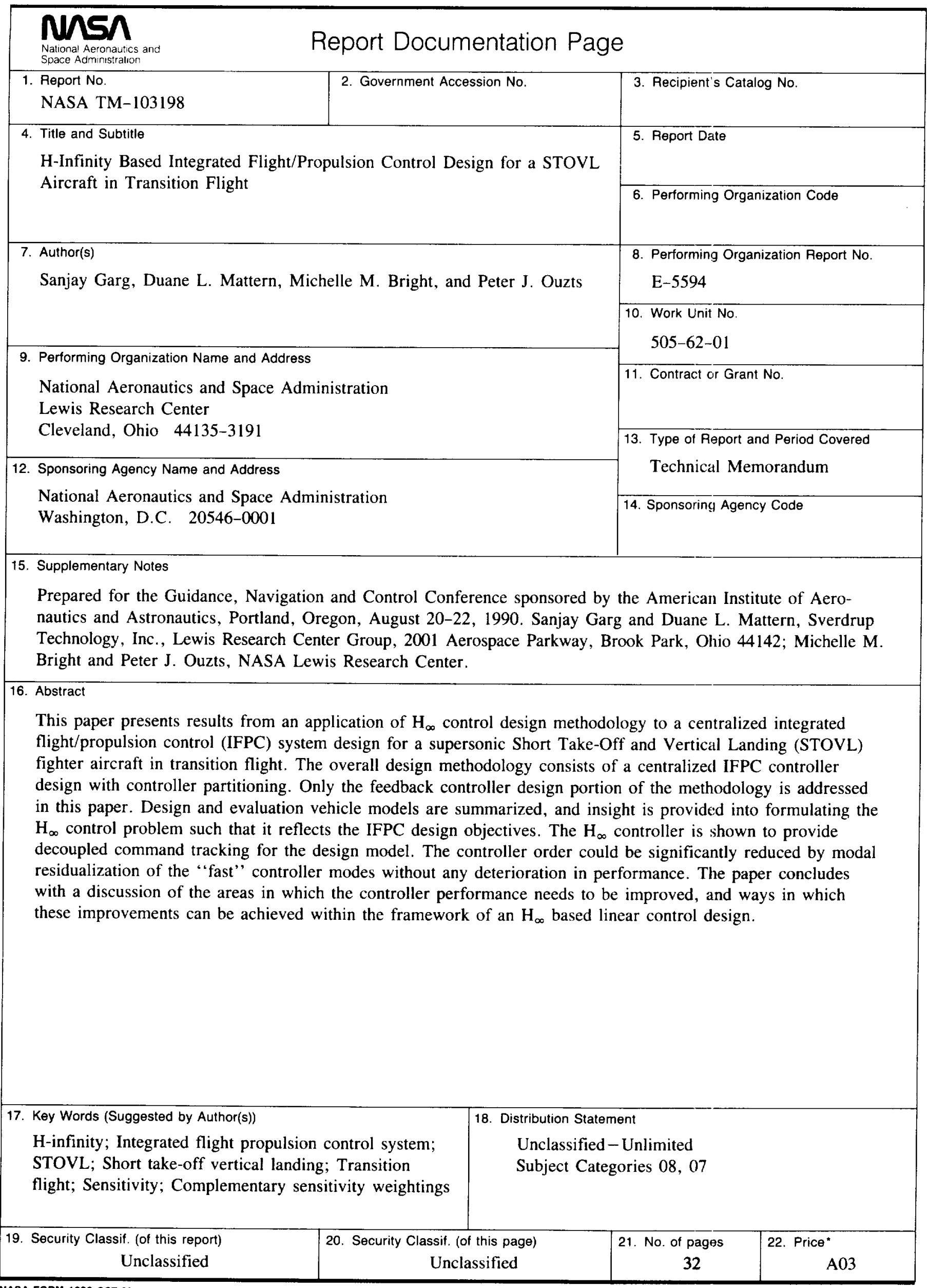




$$
\text { - - } \cdots
$$

